\title{
Bioactivities of bacterial endophytes isolated from leaf tissues of Hyptis suaveolens against some clinically significant pathogens
}

\author{
Ipsita Das ${ }^{\mathrm{a}}$, Mrunmaya Kumar Panda ${ }^{\mathrm{a}}$, Chandi C. Rath ${ }^{\mathrm{b}}$, Kumananda Tayung ${ }^{\mathrm{c}^{*}}$ \\ ${ }^{a}$ Microbial Biotechnology Laboratory, Department of Botany, North Orissa University, Takatpur, Baripada-757003, India. \\ ${ }^{\mathrm{b}}$ College of Basic Science and Humanities, Orissa University of Agriculture \& Technology (OUAT), Bhubaneswar-751003, India. \\ ${ }^{c}$ Mycology and Pathology Laboratory, Department of Botany,Gauhati University,Guwahati-781014, India.
}

\begin{tabular}{|c|c|}
\hline ARTICLE INFO & ABSTRACT \\
\hline Article history: & \multirow{9}{*}{$\begin{array}{l}\text { This study examined the antimicrobial potentials of endophytic bacteria isolated from leaf tissues of Hyptis } \\
\text { suaveolens against some clinically significant pathogens. The results indicated that } 60 \% \text { of the isolates showed } \\
\text { antimicrobial activity inhibiting at least one of the test pathogens in preliminary screening. Among them two } \\
\text { isolates showed considerable antimicrobial activity against the test pathogens. The isolates were identified as } \\
\text { Bacillus and Pseudomonas species by morphological and biochemical characterization. Phylogenetic analysis of } \\
16 \mathrm{~S} \text { rDNA sequences of the isolates showed closest homolog to an endophytic Bacillus amyloliquefaciens and } \\
\text { an endophytic Pseudomonas sp. suggesting their endophytic nature. The crude ethyl acetate extracts prepared } \\
\text { from fermentative broths exhibited moderate antibacterial and anticandidal activity both by BLIS and agar } \\
\text { diffusion assay. Enhanced antimicrobial activity was observed in nutrient broth medium amended with host } \\
\text { plant extract. Specrophotometric analysis of the crude metabolites of isolates indicate presence of bioactive } \\
\text { component. The metabolite obtained from Bacillus sp. showed a } \lambda \text {-max of } 1.541 \text { at } 254 \text { nm and that of } \\
\text { Pseudomonas sp. was } 0.155 \text { at } 250 \mathrm{~nm} \text {. Our study suggests that endophytic bacteria residing in medicinal plants } \\
\text { could be a potential source of antimicrobial agents. }\end{array}$} \\
\hline Received on: $10 / 02 / 2017$ & \\
\hline Accepted on: 11/04/2017 & \\
\hline Available online: $30 / 08 / 2017$ & \\
\hline Key words: & \\
\hline Antimicrobial activity, & \\
\hline Bacillus sp., Endophytic & \\
\hline bacteria, Hyptis suaveolens, & \\
\hline Pseudomonas sp. & \\
\hline
\end{tabular}

\section{INTRODUCTION}

Global health problems due to Drug resistance among pathogenic bacteria, inefficacy of current antifungal agents to several fungal infections and appearance of life-threatening viruses have necessitated the urgent needs for new and effective antimicrobial agents. In recent years, search for new therapeutic agents have been directed towards endophytes because of the fact that these microbes produced several novel and interesting bioactive metabolites with multiple applications. By definition endophytes are microbes that colonized inner healthy plant tissues and established for all or part of their life cycle without causing any disease symptoms (Willson, 1995). Almost all plants on this planet are believed to have association with endophytic microbes but only few of the plant species have ever been completely studied for endophytes.

\footnotetext{
* Corresponding Author

Email: kumanandbotnou@ rediffmail.com
}

The most frequently encountered endophytes are fungi, and it seems that other microbial forms certainly exist in plants as endophytes, but there is meagre information on their occurrence. So far endophytic fungi associated with medicinal plants have been thoroughly investigated due to their ability to produce myriad of bioactive metabolites (Strobel and Daisy, 2003). This gives paucity of work on other associated endophytic microbes in such plant species.In addition to fungal endophytes, occurrence of endophytic bacteria in plant species have also been reported quite extensively (Van der et al., 2009).Endophytic bacteria are reported to promote plant growth and yield and can act as biocontrol agents. It is believed that they can also be beneficial to their host by producing a range of natural products as their fungal counterpart that could be harnessed for potential Used in medicine, agriculture or industry (Ryan et al., 2008). However, little information is available on their occurrence and its potential exploitation for therapeutic uses especially those that colonized medicinal plants. 
Hyptis suaveolens is an herbaceous aromatic plant of family Lamiaceae is found throughout India. This plant is use as ethno-medicine by many tribal communities but is also considered as obnoxious weeds. Almost all parts of this plant are being used in traditional medicine to treat various diseases (Chitra et al., 2009). In Maharashtra, India, the plant is used to cure various parasitical cutaneous diseases, infection of uterus, and as sudorific in catarrhal condition, headache, stomach, snuff to stop bleeding of the nose. Owing to its several medicinal uses this plant was selected for studying the associated Endophytic bacteria and to screen the isolates for their antimicrobial potentials against a panel of clinically significant human pathogens.

\section{MATERIALS AND METHODS}

\section{Plant and sample collection}

Hyptis suaveolens grown in experimental garden of Botany Department of North Orissa University campus $\left(21^{\circ} 93\right.$ ' $\mathrm{N}$ and $86^{\circ} 76^{\prime}$ E) was selected. Healthy fresh and symptomless leaves were collected from five individual plants. The leaves were placed in sterile poly ethylene bags and brought immediately to the laboratory. The samples were washed thoroughly under running tap water and then teepol. It was then shade dried under fan before isolation procedure was undertaken.

\section{Isolation of endophytic Bacteria}

For isolation of endophytic bacteria washed leaf samples was surface sterilized by immersing them sequentially in $70 \%$ ethanol for $5 \mathrm{~min}$ and $1 \%$ sodium hypochloride $(\mathrm{NaOCl})$ for $1 \mathrm{~min}$ and rinsed thoroughly with sterile distilled water. The excess water was dried under laminar airflow chamber. The surface sterilized samples were then cut into $0.5 \mathrm{~cm}^{2}$ sizes (approx.) without midrib under aseptic conditions. Surface sterility test was performed for each sample to ensure elimination of surface microorganisms. Each fragment was then placed on basal Nutrient Agar medium (Hi-media). A total of six fragments were inoculated at equidistance per plate. The plates were incubated in BOD incubator at $30 \pm 1^{\circ} \mathrm{C}$. Bacterial growth on NA plates was observed 3-5 days after incubation. Single colonies growing out of the inoculated fragments were selected based on morphology characteristics and appearance. Pure culture was established and then subsequently sub cultured on NA slant for further study.

\section{Determination of antimicrobial activity}

Pure endophytic bacterial isolates were grown in Nutrient Broth (NB) medium and antimicrobial activity was determined against eight pathogenic bacteria (E. coli, enterotoxigenic E. coli, entero pathogenic E. coli, Bacillus subtilis, Shigellaflexneri, Staphylococcus aureus, and four pathogenic Candida species (Candida albicans, Candida tropicalis, Candida parasilopsis, Candida glabarata).

Preliminary antimicrobial activity was determined by spot inoculation and disc diffusion methods. Endophytic bacteria showing good antimicrobial activity was again subjected to secondary screening by specific assay method i.e. BLIS (Bacteriocin Like Inhibition Studies) (Mayr-Hartinget al., 1972) with slight modification. Each endophytic bacterial isolates were lawn cultured on NA plates separately by streaking perpendicularly $(0.5 \mathrm{~cm}$ wide $)$ on the middle of the plate. After 24 $\mathrm{h}$ of incubation, bacterial mass was swept out and removed thoroughly from the plates. The plates were further exposed to UV radiation for $40 \mathrm{~min}$ and on chloroform vapour for $30 \mathrm{~min}$ to ensure killing of the isolates completely. The plates were air dried for $10 \mathrm{~min}$ and then overnight cultures of test pathogens were streaked at right angles across the original growth line of the endophytic bacterial isolates and the plates were incubated at $37{ }^{\circ} \mathrm{C}$. Susceptibility to BLIS was noted when an isolate grew all the way, but not across the original line of the producer.

\section{Identification of endophytic bacterial strains}

The bacterial isolates that showed good antimicrobial activity were selected for identification by morphological, biochemical and physiological characterizations. In morphological characterization, macroscopic and microscopic features of the selected isolates were studied. Besides, an array of biochemical and physiological test including catalase test, oxidase test, indole utilization, sugar utilization, mannitol motility and Gram's staining were performed. Species confirmation was carried out by $16 \mathrm{~S}$ rDNA sequence analysis.

\section{Process optimization and Metabolite extraction}

The isolates that showed promising antimicrobial activity were cultured in different concentration of Nutrient Broth (NB) medium, medium composed of host plant extract and combination of NB and host plant extract for optimum metabolites production. The flasks containing respective medium were inoculated with the bacterial isolates and incubated in BOD shaking incubator at $30 \pm 1^{\circ} \mathrm{C}$ for 24 and $48 \mathrm{~h}$. After specified incubation Period crude metabolites of the isolates were extracted by solvent extraction method. Each liquid broth was extracted with equal volume of ethyl acetate thrice in a separating funnel by vigorous shaking for $10 \mathrm{~min}$.

The cell mass got separated and solvent so obtained was collected. Ethyl acetate was evaporated and the resultant compound was dried with Magnesium sulfate $\left(\mathrm{MgSO}_{4}\right)$ and concentrated to yield the crude extract. The crude extract was then dissolved in $10 \%$ of Dimethyl Sulphoxide (DMSO) for antimicrobial bioassay. Antimicrobial activity was determined against two gram positive bacteria (Bacillus $s$ ubtilis and Staphylococcus aureus), one gram negative bacteria (E. coli) and one pathogenic fungus ( $C$. albicans). Three replicates were maintained in each case. The metabolites were partially characterized by using a UV spectrophotometer (SPECORD 210).

\section{RESULTS}

A total of 20 endophytic bacterial isolates were obtained from surface sterilized leaf tissues of Hyptis suaveolens. The 
isolates were preliminary screened for antimicrobial activity against some clinically significant pathogens by both spot inoculation and disc diffusion methods. The result indicated that $60 \%$ of the isolates showed antimicrobial activity inhibiting at least one of the test pathogens (Table 1). Again, $25 \%$ of the isolates showed antibacterial activity inhibiting both gram positive and gram negative test pathogens. Similarly, $20 \%$ of the isolates demonstrated anticandidal activity while $10 \%$ of the isolates displayed antimicrobial activity inhibiting all the test pathogens. The isolates that showed antimicrobial activity were again subjected to secondary screening by BLIS method. Accordingly two isolates (isolates HY-05 and HY-10) that showed considerable antimicrobial activities against all the test pathogens were selected and optimized for metabolites production.

Process optimization for optimum metabolites production of both the isolates were carried out in different concentration of nutrient broth (NB) medium, host plant extract and nutrient broth medium amended with host plant extract. The isolates were inoculated into respective medium and incubated for 24 to $48 \mathrm{~h}$ in BOD shaking incubator $(150 \mathrm{rpm})$ at $30 \pm 1{ }^{\circ} \mathrm{C}$. Crude metabolites were extracted from their respective medium after $24 \mathrm{~h}$ and $48 \mathrm{~h}$ of incubation. The metabolites were determined for their antimicrobial activity against four clinically significant human pathogens. The result indicated that metabolites obtained after $48 \mathrm{~h}$ of incubation showed more activity than metabolites extracted after $24 \mathrm{~h}$ of incubation. The antimicrobial activity of the metabolites obtained from isolate HY-10 after $48 \mathrm{~h}$ of incubation in different media concentration and combination is presented in Table 2. Increased antimicrobial activity was observed in nutrient broth medium amended with host plant extract. Maximum activity was shown in the medium containing nutrient broth medium and host plant extract in the ratio $1: 1$. Very less antimicrobial activity was observed in the medium that contained only host plant extract. However, increased concentration of host extract showed antimicrobial activity against all the test pathogens. Furthermore, antimicrobial activity was observed in all concentration of nutrient broth medium but maximum activity was shown in $75 \%$ of NB medium (Table 2). Similarly, the endophytic isolate HY-05 showed considerable antimicrobial activity against the test pathogens in all concentration and media combination. Significant antimicrobial activity was observed in medium incorporated with host extract (Table 3). Nevertheless, substantial activity was also observed in the different concentration of nutrient broth medium. The isolate grown on different concentration of host extract also showed antimicrobial activity in varying degree. The bioactive metabolites dissolved in ethyl acetate were calibrated for $\lambda$-max indices using UV spectrophotometer (SPECORD 210). The crude metabolites of isolate HY-05 showed a strong signal at $250 \mathrm{~nm}$ with a maximum absorbance $(\lambda$-max) of 0.155 , while the isolate HY-10, showed signal at $254 \mathrm{~nm}$ with maximum absorbance $(\lambda$ $\max )$ of 1.541 .

The endophytic bacterial isolates, HY-10 and HY-05 were identified as belonging to genera Bacillus and Pseudomonas respectively based on their micromorphological and biochemical analysis. Molecular level confirmation was done by 16S rDNA sequence analysis. BLAST search of the sequences revealed the isolate HY-10 to be closest homolog to Bacillus amyloliquefaciens and the isolate HY-05 to be with Pseudomonas sp. The sequences of the isolates have been deposited in GenBank with accession numbers KM384035 and KM384036 respectively. To validate their endophytic nature, phylogenetic affiliation were carried out with similar named species with different lifestyles. 16S rDNA sequences of Bacillus species with endophytic, saprophytic and pathogenic lifestyle were retrieved from GenBank and 17 taxa were randomly selected. A phylogenetic tree was generated using MEGA 4.0 and generated tree showed clustering of our isolate HY-10 with an endophytic Bacillus amyloliquefaciens (Fig.1). Similarly, 16S rDNA sequences of Pseudomonas species with endophytic and saprophytic lifestyles were retrieved from GenBank and 19 taxa were randomly selected. The generated tree again showed clustering of our isolate HY-05, with an endophytic Pseudomonas sp (Fig.2).

Table 1: Preliminary antimicrobial activity of endophytic bacteria against some human pathogens.

\begin{tabular}{|c|c|c|c|c|c|c|c|c|c|c|}
\hline Bacterial Isolates & EpEc & EtEc & Ec & Bs & $\mathbf{S a}$ & Sd & $\mathbf{C a}$ & $\mathbf{C t}$ & Cp & $\mathrm{Cg}$ \\
\hline HY-1 & + & + & ++ & + & + & ++ & ++ & - & - & + \\
\hline $\mathrm{HY}-2$ & - & - & - & - & - & - & - & - & - & - \\
\hline $\mathrm{HY}-3$ & - & - & - & - & - & - & - & - & - & - \\
\hline $\mathrm{HY}-4$ & + & + & + & + & + & + & - & - & - & - \\
\hline HY-5 & + & ++ & +++ & ++ & ++ & ++ & ++ & ++ & ++ & ++ \\
\hline HY-6 & ++ & ++ & + & + & + & + & - & - & -- & - \\
\hline $\mathrm{HY}-7$ & + & + & + & - & - & - & - & - & - & - \\
\hline HY-8 & ++ & + & + & - & - & - & - & - & - & - \\
\hline HY-9 & + & ++ & - & - & - & - & - & - & - & - \\
\hline HY-10 & ++ & ++ & +++ & +++ & +++ & ++ & +++ & ++ & ++ & ++ \\
\hline HY-11 & - & - & - & - & - & - & - & - & - & - \\
\hline HY-12 & - & - & - & - & - & - & - & - & - & - \\
\hline HY-13 & + & - & - & - & - & - & - & - & - & - \\
\hline HY-14 & - & - & - & - & - & - & - & - & - & - \\
\hline HY-15 & + & - & - & - & - & - & - & - & - & \\
\hline HY-16 & + & - & - & - & - & - & - & - & - & - \\
\hline HY-17 & - & - & - & - & - & - & - & - & - & \\
\hline HY-18 & - & - & - & - & - & - & - & - & - & - \\
\hline HY-19 & - & - & - & - & - & - & - & - & - & \\
\hline HY-20 & - & ++ & ++ & + & ++ & - & ++ & + & - & ++ \\
\hline
\end{tabular}


Table 2: Antimicrobial activity of endophytic Bacillus sp. in different media combinations after $48 \mathrm{~h}$ of incubation.

\begin{tabular}{|c|c|c|c|c|c|c|c|c|c|c|c|c|}
\hline \multicolumn{13}{|c|}{ Zone of inhibition (mm) } \\
\hline \multirow[b]{2}{*}{ Test Organisms } & \multirow[b]{2}{*}{ Control } & \multicolumn{4}{|c|}{ Host Plant Extract } & \multicolumn{4}{|c|}{ Nutrient Broth } & \multicolumn{3}{|c|}{ Nutrient Broth + Host Plant Extract } \\
\hline & & $25 \%$ & $50 \%$ & $75 \%$ & $100 \%$ & $25 \%$ & $50 \%$ & $75 \%$ & $100 \%$ & $\mathbf{5 0 \%}+\mathbf{5 0 \%}$ & $75 \%+25 \%$ & $25 \%+75 \%$ \\
\hline B. subtilis & 0 & 11.3 & 13.7 & 14.5 & 14.0 & 10.2 & 13.4 & 16.3 & 15.1 & 17.1 & 14.2 & 14.6 \\
\hline S. aureus & 0 & 09.6 & 13.1 & 15.0 & 13.0 & 12.0 & 13.1 & 16.5 & 14.0 & 17.5 & 14.1 & 14.0 \\
\hline E.coli & 0 & 10.6 & 13.5 & 14.0 & 14.2 & 12.0 & 13.0 & 15.5 & 14.0 & 18.0 & 13.5 & 13.0 \\
\hline C. albicans & 0 & 08.6 & 12.0 & 14.3 & 12.3 & 11.3 & 13.2 & 13.4 & 13.0 & 16.2 & 14.0 & 14.1 \\
\hline
\end{tabular}

Value are mean of three replicates; Control- 10\% DMSO.

The total volume of each medium was $200 \mathrm{ml}$.

Table 3: Antimicrobial activity of endophyticPseudomonas sp.in different media combinations after $48 \mathrm{~h}$ of incubation.

\begin{tabular}{|c|c|c|c|c|c|c|c|c|c|c|c|c|}
\hline \multicolumn{13}{|c|}{ Zone of inhibition (mm) } \\
\hline & & \multicolumn{4}{|c|}{ Host Plant Extract } & \multicolumn{4}{|c|}{ Nutrient Broth } & \multicolumn{3}{|c|}{ Nutrient Broth + Host Plant Extract } \\
\hline Test Organisms & Control & $25 \%$ & $\mathbf{5 0 \%}$ & $75 \%$ & $100 \%$ & $25 \%$ & $\mathbf{5 0 \%}$ & $75 \%$ & $100 \%$ & $\mathbf{5 0 \% + 5 0 \%}$ & $75 \%+25 \%$ & $25 \%+75 \%$ \\
\hline B. subtilis & 0 & 14.6 & 16.0 & 16.2 & 18.2 & 19.5 & 22.0 & 24.5 & 23.6 & 27.5 & 22.2 & 21.0 \\
\hline S. aureus & 0 & 13.3 & 18.5 & 20.1 & 20.5 & 18.3 & 18.6 & 20.0 & 20.1 & 25.0 & 21.1 & 22.6 \\
\hline E.coli & 0 & 15.0 & 15.3 & 15.1 & 16.3 & 12.1 & 14.0 & 16.2 & 16.0 & 22.3 & 23.0 & 21.3 \\
\hline C. albicans & 0 & 11.2 & 12.6 & 13.0 & 13.2 & 20.0 & 24.5 & 26.0 & 24.0 & 27.0 & 19.3 & 22.0 \\
\hline
\end{tabular}

Value are mean of three replicates; Control- 10\% DMSO.

The total volume of each medium was $200 \mathrm{ml}$.

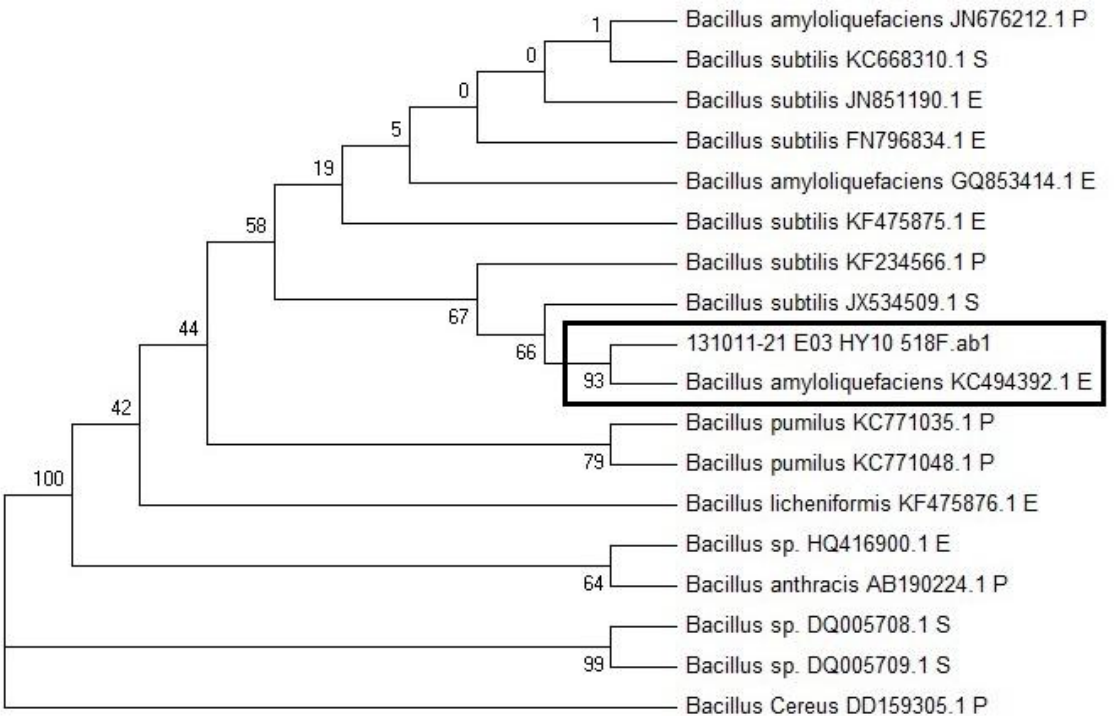

Fig.1: Phylogenetic affiliation of 16S rDNA sequences of 18 taxa of Bacillus spp. with saprophytic (S), pathogenic (P) and endophytic (E) lifestyles.

The rectangular box indicates our own isolate, HY-10 clustered with an endophytic Bacillus amyloliquefaciens.

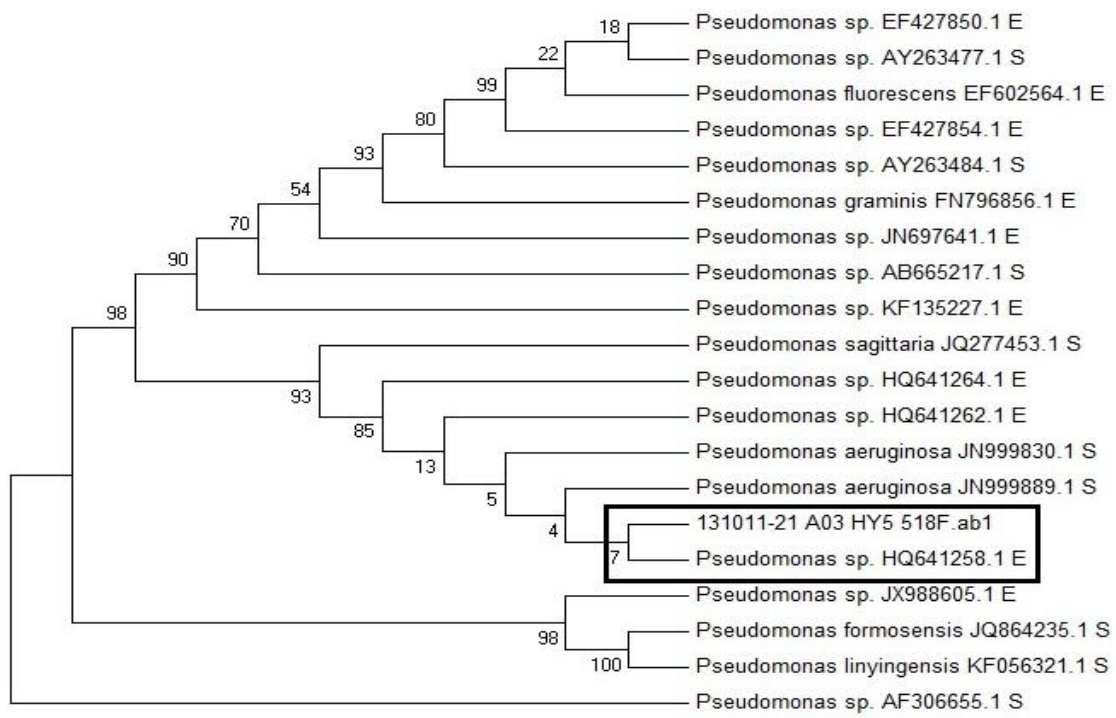

Fig.2:Phylogenetic affiliation of 16S rDNA sequences of 20 taxa of Pseudomonas spp. with saprophytic (S), pathogenic (P) and endophytic (E) lifestyles The rectangular box indicates our own isolate HY-05 clustered with an endophytic Pseudomonas sp. 


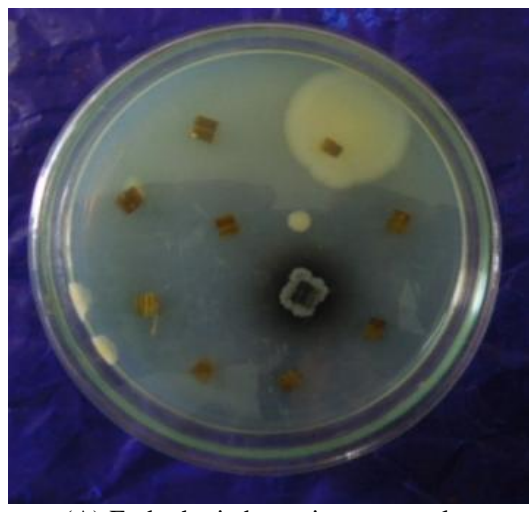

(A) Endophytic bacteria on agar plates

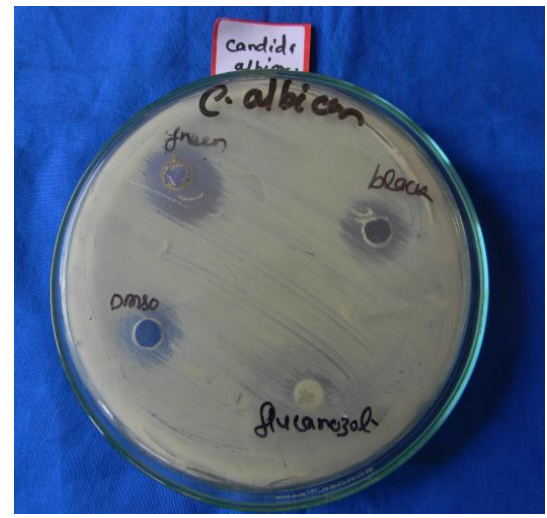

(D) Antifungal activity of the crude metabolites against Candida albicans.

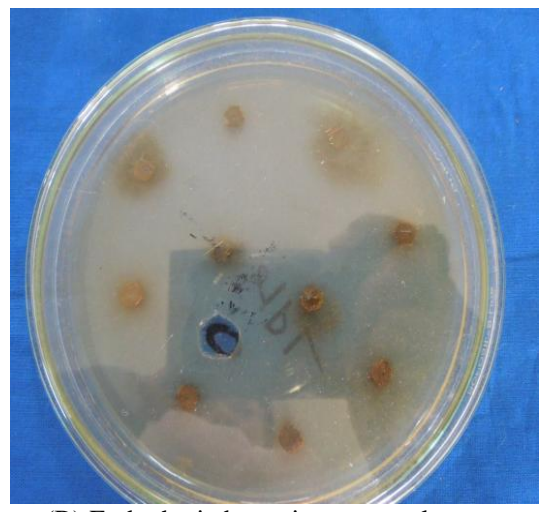

(B) Endophytic bacteria on agar plates

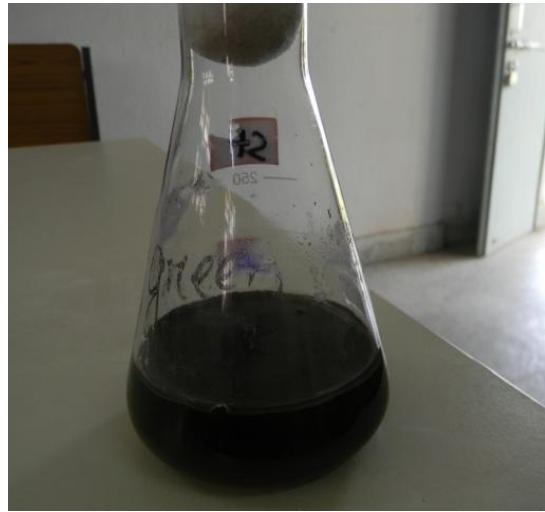

(E) Isolate Hy-5 on solid media

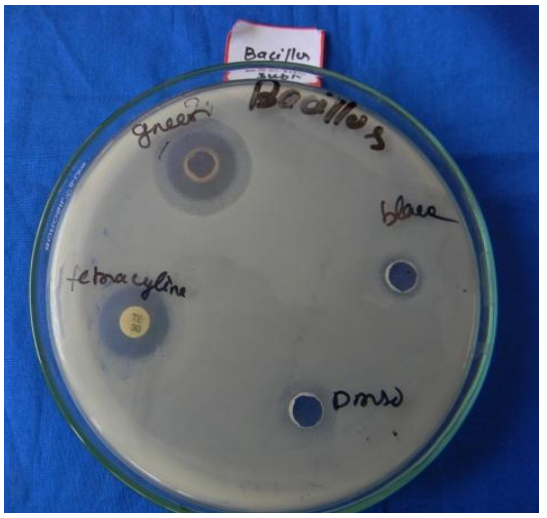

(C) Antibacterial activity of the crude metabolites Against Bacillus subtilis

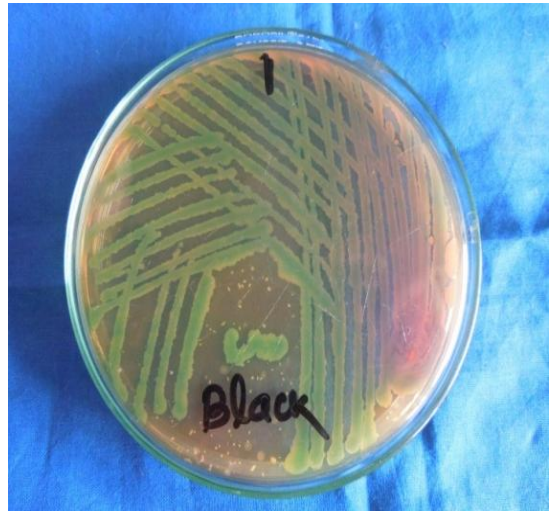

(F) Isolate Hy-10 on Hichrome Bacillus agar

\section{DISCUSSION}

The study revealed colonization of endophytic bacteria in the leaf tissues of Hyptis suaveolens, an herbaceous aromatic plant of family Lamiaceae. Similarly, several workers have also reported their occurrence in various plant species (Hallmann et al., 1997; Rosenblueth and Martínez-Romero, 2006). It is a well-known fact that plants are associated with various types of microorganisms. Some of them are present as epiphytes while other inhabits inner plant tissues and established as endophytes. Among different microbes that reside as endophytes, bacterial endophytes are quite distinct and found colonized in different plant parts. They have been isolated from both herbaceous plants as well as woody trees. This suggests that they are distributed ubiquitously in plant kingdom.

The functional roles of bacterial endophytes have been well elucidated. They are known to increase host plants resistance to pathogens and promote biological nitrogen fixation (Bhore et al., 2010). Besides, studies have demonstrated that they mediate de novo synthesis of novel antimicrobial compounds and antifungal metabolites (Wellington and Marcela, 2004). This has also been exemplified in our present study, in which $60 \%$ of the endophytic bacterial isolates showed antimicrobial activity inhibiting at least one of the test pathogens and two of the isolates exhibited considerable antimicrobial activity against the test pathogens. Studies have suggested that endophytic microbes could produce bioactive components as their respective host. This has been well reported in taxol producing endophytic fungus Taxomyces andreanae isolated from Pacific yew (Stierle et al., 1993). Thus, it can be attributed that the antimicrobial activity of the endophytic bacteria may be due host derived metabolites as the plant chosen for this study, Hyptis suaveolens produces various phytochemicals which are reported to be antimicrobial in nature (Pachkore et al., 2011).

The two endophytic bacteria which showed significant antimicrobial activity was identified as a Bacillus sp. which is a gram-positive and a Pseudomonas sp. which is gram-negative bacteria. Occurrence of both gram-positive and gram-negative endophytic bacteria has been reported from large diverse terrestrial and aquatic plants (Sturz et al., 2003). Bacteria of the genera Bacillus and Pseudomonas are dominant rhizospheric bacteria but have also been reported as endophytes in several plant species (Sun et al.,2013). The Bacillus sp. was found to be closest homolog to an endophytic Bacillus amyloliquefaciens and the Pseudomonas sp. revealed closest affinity with an endophytic Pseudomonas species suggesting their endophytic nature. In many instances, these bacterial genera have been reported to produce antimicrobial and other bioactive metabolites. Chao et al. (2013) 
reported broad antifungal metabolites from endophytic Bacillus amyloliquefaciens isolated from healthy Cinnamomum camphora leaves. Similarly, Yuan et al. (2012) reported anti-sapstain fungal activity of Bacillus amyloliquefaciens isolated from Chinese medicinal plant, Ginkgo biloba. Endophytic Pseudomonas has also been reported to produced antimicrobial metabolites. Pseudomycins represent a group of peptide antifungal compounds isolated from liquid cultures of Pseudomonas syringae, a plantassociated bacterium and found to be highly active against fungal pathogens like Candida albicans and Candida neoformans(Harrinson et al., 1991). Likewise, Ecomycins representing a family of novel lipopeptides produce by fluorescent Pseudomonads that exist as endophytes in the tissues of many grass species have also been reported to have antifungal activity (Isogai et al., 1990). Such findings suggest that endophytic bacteria residing in plant tissues could be novel sources of bioactive metabolites.

The nutritional requirements of endophytic bacteria have not been well documented (Baldani et al., 1997) divided them into two main types namely, obligate and facultative. The facultative forms are capable of surviving in the soil, on the plant surface, inside the plants as well as on artificial nutrients while the obligate endophytes inhabit inside plant tissues throughout their lifespan. In the present study, the endophytic bacterial isolates were grown in different media concentrations and media amended with host extract to maximize their metabolites production. Although no significant difference in their activity was noted at different concentrations but increased in metabolites activity was observed in the medium amended with host plant extract. Similar results were obtained by Yuan et al .(2012) in which enhanced anticandidal activity was noted in endophytic fungus, Phomopsis sp. ED2, isolated from Orthosiphon stamineus by incorporation of host plant extract in culture medium. This suggests that the host plant may contain some molecules that act as inducer or precursor for the production of more antimicrobial metabolites by the colonizing endophytes. Our study suggests that endophytic bacteria residing in medicinal plants could be a potential source of novel antibiotics and the probability of getting potent endophytic bacteria is great considering the myriad of medicinal plants in the planet. Currently, efforts are on to characterize and elucidate the active fraction of the metabolites produced by the endophytes.

\section{ACKNOWLEDGEMENT}

The corresponding author acknowledges University Grant Commission (UGC), New Delhi, Government of India for financial support in the form of UGC Research Award.

\section{Conflict of interest statement}

We declare that we have no conflict of interest.

\section{REFERENCES}

Baldani JI, Baldani VL, Goi S, Dobereiner J. Recent advances in BNF with non-legume plants. Soil Biol Biochem, 1997, 29:911-922.

Bhore SJ, Nithya R, and Loh CY. Screening of endophytic bacteria isolated from leaves of Sambung Nyawa [Gynuraprocumbens (Lour.) Merr.]forcytokinin-like compounds. Bioinformation, 2010, 5:191197.

Chao CX, Hui L, Rong X, Hong L. Study of endophytic Bacillus amyloliquefaciens $\mathrm{CC} 09$ and its antifungal cyclic lipopeptides. Journal of Applied Biology and Biotechnology, 2013,1:pp.1-5.

Chitra S, Patil M B and Ravi Kumar. Wound Healing Activity of Hyptis suaveolens(L.) Poit (Lamiaceae). International Journal of PharmTech Research, 2009,3: 737-744.

Hallmann J, Quadt-Hallmann A, Mahaffee W, and KloepperJ.Bacterialendophytes in agricultural crops.Can J Microbiol, 1997,43:895-914.

Harrison LH, Teplow DB, Rinaldi M, and Strobel, G. Pseudomycins, a family of novel peptides from Pseudomonas syringae possessing broad-spectrum antifungal activity. J Gen Microbiol , 1991,137:2857-2865.

Isogai A, Fukuchi N, Yamashita S, Suyama K, Suzuki A. Structures of syringostatins A and B, novel phytotoxins produced by Pseudomonas syringaepv. Syringae from lilac blights. Tetrahedron Lett, 1990, 31:1589-1592.

Mayr-Harting A, Hedges AJ. And Berkeley RCW.Methods for studying bacteriocins.In Methods in Microbiology.Academic Press,New York, 1972: 315-342.

Pachkore GL, Dhale DA, and DharasurkarAN. Antimicrobial and phytochemical screening of Hyptis suaveolens(L.Poit) Lamiaceae. International Multidisciplinary Research Journal 2011, 1(4):01-03

Rosenblueth M, Martinez-Romero E. Bacterial endophytes and their interactions with hosts. Phytopathology, 2006, 19:827-837.

Ryan RP, Germaine K, Franks A, Ryan DJ. Bacterial endophytes: recent developments and applications. FEMS Microbiol.Lett, 2008,278: 1-9.

Stierle A, Strobel G, Stierle D. Taxol and taxane production by Taxomyces andreanae, an endophytic fungus of Pacific yew.Science, 1993, 260: 214-216.

Strobel G, Daisy B. Bioprospecting of microbial endophytes and their natural products. Microbiol.Molecular. Biol. Rev,2003, 67(4): 491-502

Sturz AV, Christie BR, Nowak J. Bacterial endophytes: Potential role in developing sustainable systems of crop production. CRC Crit Rev Plant Sci,2003, 19:1-30.

Sun, H., He, Y., Xiao, Q., Ye, R., and Tian, Y.Isolation, characterization, and antimicrobial activity of endophytic bacteria from Polygonum cuspidatum.Afr. J. Microbiol,2013, 7(16): 1496-1504

Van der Lelie D, Taghavi S, Monchy S. Poplar and its bacterial endophytes: coexistence and harmony. Crit Rev Plant Sci , 2009,28:346358.

Wellington B, Marcela T. Delivery methods for introducing endophytic bacteria into maize. BioControl, 2004, 49: 315-322.

Willson, D.Endophyte - The Evolution of a Term, And Clarification of Its Use and Defination. Oikos, 1995, 73(2): 274-276.

Yuan Bo, WangaZhe, QinaSheng, ZhaoGui-Hua, FengYouJian, Wei Li-Hui, Jiang Ji-Hong.Study of the anti-sapstain fungus activity of Bacillus amyloliquefaciens CGMCC5569 associated with Ginkgo biloba and identification of its active components. Bioresour.Technol, 2012,(12):536-541.

How to cite this article:

Das I, Panda MK, Rath CC, Tayung K. Bioactivities of bacterial endophytes isolated from leaf tissues of Hyptis suaveolens against some clinically significant pathogens. J App Pharm Sci, 2017; 7 (08): 131-136. 